\title{
A pilot study on utility of salivary glucose levels to monitor diabetes mellitus
}

\author{
V. Priyanka ${ }^{1, *}$, Kotya Naik Maloth ${ }^{2}$ \\ ${ }^{1}$ Reader, Dept. of Oral Medicine and Radiology, Sri Balaji Dental College, Hyderabad, Telangana, ${ }^{2}$ Reader, Dept. of Oral \\ Medicine and Radiology, Mamata Dental College and Hospital, Khammam, Telangana, India \\ *Corresponding Author: V. Priyanka \\ Email: priyanka.036@gmail.com
}

\begin{abstract}
Aim: To utilize salivary glucose levels as a measure to monitor Diabetes mellitus.

Materials and Methods: The fasting whole saliva and serum was collected from 100 type 2 diabetes mellitus patients and were analyzed for glucose. The results were analyzed statistically.

Results: In this study a good correlation was observed between salivary and serum glucose levels

Conclusion: Salivary glucose levels can serve as a marker in diagnosing and monitoring type 2 diabetes mellitus.
\end{abstract}

Keywords: Diabetes mellitus, Salivary glucose, Serum glucose.

\section{Introduction}

The Type 2 Diabetes mellitus is the most widely spread disease these days. Diabetes mellitus (DM) is caused by a insufficiency of insulin secretion. ${ }^{1}$ Diabetes mellitus (DM) has been classified into Type1 DM, Type $2 \mathrm{DM}$, gestational DM and other specific types ${ }^{2}$ Type 1 diabetes accounts for $10 \%$ of population and type 2 diabetes mellitus accounts for $90 \%$ of population. $^{3}$

Diabetes mellitus affects approximately 14 million people in United States and majority are often undiagnosed. ${ }^{4} 19.4$ million individuals in India are affected with this deadly disease, which is likely to go up to 57.2 million by the year $2025 .{ }^{4}$ DM may lead to potential complications like the diabetic retinopathy, nephropathy, peripheral peripheral neuropathy, macroangiopathies, etc. ${ }^{5}$

Hence the investigative procedures must be routinely employed to diagnose and monitor the diabetes. The most routinely employed procedures are blood investigations. These procedures are invasive and offer much discomfort to the patient. So, there is a pressing need for the development of non-invasive procedure method for diagnosing and monitoring diabetes.

Changes in the basement membrane of salivary glands in diabetes enhances increased permeability of glucose molecules in saliva thus enabling detection of salivary glucose levels ${ }^{6}$ which is helpful in detecting DM. Saliva has added benefits over blood. The saliva collection is non-invasive and is less complicated than collecting serum glucose. For larger populations saliva also serves as a cost effective approach.

This study is undertaken to validate the utility salivary glucose levels as a measure to monitor Diabetes mellitus. The correlation between salivary and serum glucose levels has got advantage of being a noninvasive method of monitoring diabetes mellitus.

\section{Materials and Methods}

Type 2 diabetes mellitus patients under the treatment reporting to reporting to Osmania general hospitals, Hyderabad, were considered under study group.

A total of 100 patients with type 2 diabetes mellitus were included in the study and their age ranges between $30-75$ years. Similarly 100 people were taken in the control group between the same age group. Collection of fasting serum and saliva were performed between 6$9 \mathrm{am}$.

The blood is collected into $2 \mathrm{ml}$ test-tube containing $20 \mu 1$ of fluoride oxalate which prevents clotting of blood and degradation of glucose. ${ }^{2}$ The unstimulated whole saliva was analyzed in this study. $1 \mathrm{ml}$ of saliva was collected in draining method in a plastic container which is placed over icepack containing $0.1 \mathrm{ml}$ of sodium fluoride is added to prevent degradation of glucose. ${ }^{3}$ The plastic containers with saliva are stored in ice until analysis of glucose is performed. The Glucose levels in both the samples were analyzed using glucose oxidase/peroxidase reagent in Biolis $4 \mathrm{i}$ autoanalyzer and the results were recorded.

\section{Results}

A significant relationship is observed between the salivary and serum glucose levels type 2 diabetics and controls. Pearson correlation test value for study and control group was 0.99 and 0.89 respectively. This remarkably shows that the salivary glucose levels increases with increasing serum glucose levels. A statistically significant ' $\mathrm{P}$ ' value was obtained for both serum and salivary glucose levels which was $<0.01$. (Table 1 and Graph 1) 
Table 1: Serum and salivary glucose levels correlation in type 2 diabetics and controls

\begin{tabular}{|c|c|c|c|c|c|c|c|}
\hline & Type II & $\begin{array}{c}\text { Sample } \\
\text { Size }\end{array}$ & $\begin{array}{c}\text { Range } \\
\mathbf{m g} \%\end{array}$ & $\begin{array}{c}\text { Mean } \\
\mathbf{m g} \%\end{array}$ & $\begin{array}{c}\text { Standard } \\
\text { Deviation }\end{array}$ & $\begin{array}{c}\text { Pearson } \\
\text { correlation } \\
\text { value 'r' }\end{array}$ & P Value \\
\hline $\begin{array}{c}\text { Diabetic } \\
\text { S }\end{array}$ & $\begin{array}{c}\text { Serum Glucose } \\
\text { Levels }\end{array}$ & 100 & $100-247$ & 191.2 & 52.464 & 0.99 & $<0.01$ \\
\cline { 2 - 6 } & $\begin{array}{c}\text { Salivary Glucose } \\
\text { Levels }\end{array}$ & 100 & $9.9-29.67$ & 19.13 & 5.1857 & & \\
\hline Controls & $\begin{array}{c}\text { Serum Glucose } \\
\text { Levels }\end{array}$ & 100 & $73-120$ & 93.68 & 12.305 & 0.89 & $<0.01$ \\
\cline { 2 - 6 } & $\begin{array}{c}\text { Salivary Glucose } \\
\text { Levels }\end{array}$ & 100 & $7.4-12.9$ & 9.713 & 1.2369 & & \\
\hline
\end{tabular}

Unpaired ' $\mathrm{t}$ ' test

Graph 1: Correlation of serum and salivary glucose levels in type 2 diabetics

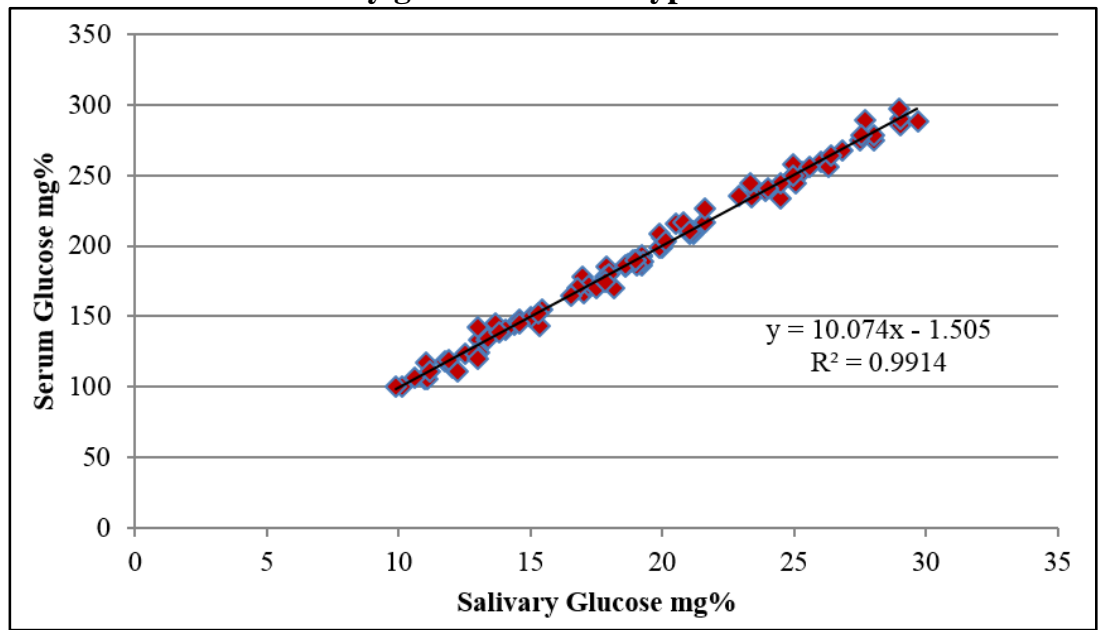

\section{Discussion}

$\mathrm{DM}$ is the $5^{\text {th }}$ most common metabolic disorder routinely encountered in the world. Due to the modified lifestyle habits, the prevalence of DM has drastically raised. People detected with diabetes will rapidly increase to 366 million by $2030 .{ }^{8}$ The number of diabetic patients is estimated to increase to 79.4 million by 2030 in India. ${ }^{9}$

This metabolic disease is a potential burden because of the high morbidity and mortality associated with infections and delayed wound healing. DM also affects other main organs in the body like kidney, eye and blood vessels. Thus, it is essential to take necessary steps for the early detection and control of DM with regular monitoring over glycemic control.

The routinely employed investigative procedures for glucose monitoring are invasive, but saliva can best serve as a valuable non invasive diagnostic aid. Thus the correlation between salivary and serum glucose levels would be helpful in monitoring diabetes noninvasively. There is paucity on the data regarding its correlation, hence this study was undertaken to validate the utility of salivary glucose concentration in diabetics, and also to explore the potential validity of using saliva for diagnosing and monitoring DM.
Hyderabad ranks first in India with having $4.1 \%$ of prevalence in type $1 \mathrm{DM}$. The probable etiology for higher prevalence in Andhra Pradesh would be because of more consumption of polished rice, where as in other states wheat, jowar and bajra are consumed more. ${ }^{10}$

DM can be detected by measuring salivary glucose levels. The glucose molecule easily diffuses into salivary gland through the semi permeable membrane. Thus, with the increase in blood glucose levels the salivary glucose levels also increases. The glucose molecule enters into saliva because of the permeability of basement membrane of salivary glands. ${ }^{11}$ Under pathologic conditions like the infections and inflammations of salivary glands raised glucose levels can be detected.

A statistically significant ' $\mathrm{p}$ ' value $(\mathrm{P}<0.01)$, was obtained in this study and the salivary glucose are higher in type- 2 diabetics than in controls and was statistically highly significant this is in accordance with the findings of Johansson et al. ${ }^{12}$

In the present study a remarkable interconnection is seen in the between levels of serum and salivary glucose levels. Hence, salivary glucose serves as a reliable indicator of serum glucose concentrations in diabetes. The same correlation was noticed by Sreedevi et al, ${ }^{7}$ Yamaguchi et al. ${ }^{13}$ 
A correlation was found both in fasting and after glucose load according to a study. ${ }^{14}$ This correlation was in contrary to Borg A and Birkhed D, whose observations show that the correlation was higher after than before the carbohydrate intake, ${ }^{15}$ Anderson $\mathrm{AB}$ et al. showed that the glucose concentration is increased after $2 \mathrm{hrs}$ after glucose intake in patients with both IGT and DM of short duration. ${ }^{16}$ In certain studies correlation was seen only in fasting glucose levels of saliva and blood. ${ }^{17}$

As the time duration of the entry of glucose into salivary glands is not determined precisely and in order to avoid biased results in this study only fasting glucose levels are considered.

As variation in the correlation was observed in various studies while using gland specific saliva, in the present study resting unstimulated whole saliva is considered and in order to standardize the salivary measures all the samples are collected between 6-9 am.

For a given salivary glucose level by using the regression equation the serum glucose level can also be predicted [Serum glucose $=10.07$ (salivary glucose) 1.505], for type 2 diabetes.

It is observed in the study that if the salivary glucose levels are greater than $11.5 \mathrm{mg} \%$ the patient is considered as diabetic and if the values are less than $11.5 \%$ the patient is considered as non diabetic. The overall accuracy of the study is $95.6 \%$, sensitivity is 95.5\% and specificity is $95.9 \%$. Positive predictive value is $96.4 \%$ and $95.2 \%$ is the negative predictive value.

Our study showed a good interconnection among serum and salivary glucose levels. So, salivary glucose levels may be used diagnose diabetes mellitus as has got profound advantage of being a non invasive method and is potentially valuable. Detailed information on glucose levels in saliva and further studies which include random and post prandial glucose comparison would further help in inculcating salivary glucose levels as a promosing source to monitor and detect DM.

\section{Conclusion}

Diabetes mellitus is the most prevailing chronic disease that requires long-term medical attention to limit the development of its devastating complications. The routinely employed investigative procedures are invasive whereas salivary glucose levels can serve as a non invasive diagnostic modality for diagnosing and monitoring salivary glucose levels.

A good interconnection was found between salivary and serum glucose in type 2 DM patients. A patient can monitor the diabetes based on salivary glucose levels. In near future further research must be carried to recommend salivary glucose levels to monitor DM.

\section{References}

1. Garber A, Diabetes mellitus, Internal medicine. 1998;1850-1854.

2. American Diabetes Association. Diagnosis and classification of diabetes mellitus. Diabetes care. 2010;33:S62-9.

3. Harris MI, et al. Prevalence of diabetes, impaired fasting glucose, and impaired tolerance in US adults. The third National Health and Nutrition Examination Survey.19881994. Diabetes Care. 1988;21:518-24.

4. Pradeepa R, Deepa R, Mohan V. Epidemiology of diabetes in India--current perspective and future projections. J Indian Med Assoc. 2002;100:144-8.

5. Byron J Hoogwerf. Complications Of diabetes mellitus. Int. J diab Dev Countries. 2005;25:63-69.

6. Murrah V A, Crusson J T, Sauk JJ. Parotid gland basement membrane in diabetes mellitus. J Oral Path. 1985;14:236-46.

7. Sreedevi, Shashikanth MC, Shambulingappa P. Comparisison of serum glucose and salivary glucose in diabetic patients. JIAOMR. 2008;20:9-12.

8. Ramachandran A, Snehalatha C, Kapur A, Vijay V, Mohan V, Das AK, et al. Diabetes Epidemiology Study Group in India: High prevalence of Diabetes and impaired glucose tolerance in India: National Urban Diabetes Survey. Diabetologia. 2001;44:1094-1101.

9. Wild S, Roglic G, Green A, Sicree R, King H. Global prevalence of Diabetes: estimates for the year 2000 and projections for 2030. Diabetes Care. 2004;27:1047-53.

10. Epidemiology of Diabetes of Indians in Asian Subcontinent. Indian journal of diabetology. 2010.32-36.

11. Sharon A, Ben-Aryeh H, Itzhak B, Yoram K, Szargel R, Gutman D. Salivary composition in diabetic patients. $J$ Oral Med. 1985;40:23-6.

12. Johansson I, Saellstrom AK, Rajan BP et al. Salivary flow and dental caries in Indian children suffering from chronic malnutrition. Caries Res. 1992.26:38-43.

13. Yamaguchi M, Mitsumori M, Kanon Y. Development of non invasive procedure for monitoring blood glucose levels using saliva. Am J Physiol.1958;192:482-4.

14. Feller RP, Shannon IL. The secretion of glucose by the parotid gland. AADR Abstract No.1975, published in $J$ Dent Res. 1975;50:57.

15. Borg A, Birkhed D. Secretion of glucose in human parotid saliva after carbohydrate intake. Scand J Dent Res. 1988;96:551-6.

16. Anderson AB, Birkhed D, Berntorop K, Lindgarde F, Matsson L. Glucose concentration in parotid saliva after glucose/ food intake in individuals with glucose intolerance and diabetes mellitus. Eur J Oral Sci. 1998;106:931-37.

17. Marchetti P, Tognarelli M, Giannarelli R, Grossi C, Picaro L, Carlo A et al. Decreased salivary glucose secretory rate : Usefulness for detection of diabetic patients with autonomic neuropathy. Diabetes Res. Clinical Practice. 1989;7:181-6. 